\title{
EN MEMORIA DE CHRISTOPHER PLATT
}

GUIDO DI TELLA

Embajador de Argentina

Washington, D.C.

El Profesor D. C. M. Platt, fallecido el 15 de agosto de 1989 en Oxford, tenía la rara cualidad de escribir con facilidad temas pensados en profundidad y con rigor, el mismo que exigía de sus colegas. Rigor en el análisis, en los datos, en las fuentes, aspectos que lo obsesionaron en particular en los últimos años. No en vano gustaba citar aquello de que «en un mundo como el nuestro, para que valga la pena regar un jardín (debiéramos saber), si está o no plantado con flores de papel». Esta obsesión por distinguir las flores falsas de las verdaderas lo llevó a replantearse la validez cuantitativa de muchas de las afirmaciones relacionadas, sobre todo, con los movimientos y flujos de capital.

Sus análisis del monto de las inversiones británicas, primero en el Río de la Plata y luego en el mundo, en torno de la primera Guerra Mundial, lo llevaron a nuevas y mucho más bajas estimaciones de los flujos de capital desde Gran Bretaña hacia el resto del mundo. A partir de estos análisis hechos de manera simple pero ingeniosa se podian deducir dos consecuencias: por un lado, que el problema de la dependencia, por lo menos de los capitales, no había sido tan grande y, por el otro, que, si había habido depen. dencia, ésta no estaba tan justificada en función de los más modestos capitales obtenidos. El Profesor Platt gustaba señalar estas paradójicas conclusiones que mostraban cómo más que versiones sectarias con conclusiones a priori, sólo una visión imparcial y objetiva puede permitir entender al mundo en su complejidad.

Luego de obtener el DPhil. en la Universidad de Oxford, en 1962, pasó a desempeñarse en Exeter (1962-68). Ya en la Universidad de Cambridge (Queens) dirigió el Centro de Estudios Latinoamericanos (1968-72), designación que precedió a otra análoga en Oxford, como Profesor Titular a cargo hasta 1983 del Centro de Estudios Latinoamericanos que tanto impacto ha tenido en el área de especialización. El St. Anthony's College lo tuvo como a uno de sus más conspicuos miembros. 
Una enfermedad prematura hizo temer con respecto a su actividad. Esto no sólo no ocurrió, sino que precedió toda una sucesión de importantísimos libros en los que dejó registrado su ampliado interés, que pronto excedió el ámbito latinoamericano, tales como Finance, Trade and Politics in British Foreign Policy 1815-1940 (1968); The Cinderella Service, British Consuls since 1825 (1961); Latin America and British Trade 1806-1914 (1972); Britain's Investment Overseas on the Eve of the First World War, Use and Abuse of Numbers (1984), y Foreign Finance in Continental Europe and the U.S.A. 1815-1870 (1984), mostrándose en particular en este último su integridad $\mathrm{e}$ independencia de criterio basado en los archivos Baring.

Editó también cuatro libros: Business Imperialism; An Inquiry Based on British Experience in Latin America before 1930 (1977); Argentina, Australia and Canada: Studies in Comparative Development 1870-1965 (1985) y sobre los mismos paises: Studies in Social Development (1988) y The Political Economy of Argentina 1880-1946 (1986), libros en los que la interrelación entre el comercio, el flujo de capitales y el desarrollo, económico y social, fueron el tema central.

Su último libro, Mickey Mouse Numbers (1989), es una prueba tanto de su coraje intelectual como de su enfoque ácido, penetrante e irónico sobre la excesiva ligereza de muchas de las cuantificaciones históricas, incluso de algunas muy prestigiadas, muchas de ellas consecuencia de citas entre académicos sin controlar el origen primario, a veces muy endeble, de la primera de ellas.

El Profesor Platt fue uno de los productos más complejos de la formación Oxoniana, tanto por su estilo, su coraje ante la adversidad, su humor. su determinación y su buen talante, que surgía naturalmente, sobre todo, en las reuniones privadas.

No hay duda de que la influencia morigeradora de su análisis ha influido e influirá en los estudios sobre estos temas, que tomarán en consecuencia orientaciones distintas. La polémica desatada por el Profesor Platt tardará un buen tiempo antes de cerrarse.

Finalmente, otro aspecto fundamental de su compleja personalidad que no puede dejar de mencionarse es la amistosa atención y el generoso uso de su tiempo brindado tanto a sus alumnos como a sus colegas, de los que he podido ser testigo y beneficiario.

Hay poca duda que, parafraseando su cita preferida, podemos decir que las flores que él plantó han producido y producirán nuevos, ricos y significativos frutos. 